\title{
Clinical Feasibility of Wearable Robot Orthosis on Gait and Balance Ability for Stroke Rehabilitation: A Case Study
}

\author{
Young-II Shin', Seong-Hwa Yang' ${ }^{2}$ Jin-Young Kim³ \\ 'Deptartment of Prosthetics \& Orthoics, Korea National University of Welfare, Pyeongtaek; ${ }^{2}$ Department of Physical Therapy, Gyeonggi-Incheon \\ Medical Rehabilitation Center, Incheon; ${ }^{3}$ Department of Occupational Therapy, Howon University, Gunsan, Korea
}

Purpose: The emphasis on gait rehabilitation after stroke depends on training support through the lower limbs, balance of body mass over the changing base of support. However, muscle weakness, lack of control of lower limb, and poor balance can interfere with training after stroke. For this case study report, a wearable robot orthosis was applied to stroke patients in order to verify its actual applicability on balance and gait ability in the clinical field.

Methods: Two stroke patients participated in the training using the wearable robot orthosis. Wearable robot orthosis provides patientinitiated active assistance contraction during training. Training includes weight shift training, standing up and sitting down, ground walking, and stair up and down Training was applied a total of 20 times, five times a week for 4 weeks, for 30 minutes a day. Gait ability was determined by Stance phase symmetry profile, Swing phase symmetry profile, and velocity using the GAITRite system. Balance ability was measured using the Biodex balance system.

Results: Subjects 1, 2 showed improved gait and balance ability with mean individual improvement of 72.4\% for velocity, 19.4\% for stance phase symmetry profile, $9.6 \%$ for swing phase symmetry profile, and $13.6 \%$ for balance ability.

Conclusion: Training utilizing a wearable robot orthosis can be useful for improvement of the gait and balance ability of stroke patients.

Keywords: Balance, Gait, Robot rehabilitation, Stroke

\section{서 론}

뇌졸중 재활에서 보행능력의 회복은 가장 중요한 치료목표 중 하나 이다. 독립적인 보행을 위한훈련은 다리를 통한 지지와 뒤꿈치떼기, 변화하는 지지면에서 균형잡기에 중점을 두고 있다. 보행 기능 훈련 에 있어서 과제지향적훈련(task-oriented training)은 보행 자체를 배제 한다는 것이 아니라 의자에서 일어나기 및 선 자세에서 앉기 등과 같 은 보행 관련 활동들의 훈련필요성을 강조한다. ${ }^{2}$ 많은 치료사들은 신 경계재활에서 직접적인 손의 접촉을 통해 치료하고 있다. 능동보조 운동과 손기술은 보바스나 고유수용성신경근촉진법에서 많이 사용 되고 있다. ${ }^{34}$ 그러나 보행 훈련을 반복적이고 안전하게 시행하기 위해 서는 치료사의 신체적 부담이 가해지고, 치료사의 숙련도 등에 따라 보행 훈련의 재연성에 문제가 나타난다.

이러한 문제점을 극복하기 위한 여러가지 로봇재활장치들이 개발
되고 있다. 최근 개발된 새로운 장비는 환자에게 독립적으로 동작과 연습을 더 많이 반복하게 함으로써 신체적 활동을 하는 데 시간을 증가시킬 수 있다. 장비들을 사용하면서 되먹임을 제공하고, 신체적 참여를 이끌 수 있고, 연습의 강도와 동기를 증가시킨다. ${ }^{5}$ 하지재활로 봇은 치료실 수준에서뿐만 아니라, 옷처럼 입을 수 있는 외골격로봇 의 형태로 제작되어 지상보행트레이너(overgound gait trainers) 역할을 하는 로봇들이 사용되고 있다. ${ }^{6}$ 로봇재활장치는 중추신경계통의 손 상 후에 부분적으로 자동적인 움직임 훈련을 시킬 수 있다. 현재 가 장 널리 보급된 보행재활로봇은 트레드밀 위에서 체중지지를 통해 관절의 움직임을 돕는 제어시스템이다. 하지만 로봇시스템은 전통적 인 체중지지트레드밀과 마찬가지로 움직임 훈련의 본질적인 균형과 의도된 요구, 시각흐름(visual flow)을 포함하지 못한다.

최근에는 뇌졸중 후 무릎관절 폄근의 기능을 보완하고, 착용 후 이동이 가능하고, 의도기반으로 작동하는 로봇이 개발되었다. 아직 
까지 착용형 로봇연구의 임상적 적용에 대한 연구는 극히 미미한 수 준이다. 본 연구의 목적은 뇌졸중 환자에게 착용형 로봇보조기가 보 행의 시공간적 변수와 균형에 미치는 영향을 알아보고자 한다.

\section{연구방법}

\section{1. 대상자}

본 연구는 인천시에 위치한 $\mathrm{K}$ 재활센터에서 연구취지를 이해하고 참 여에 동의한 뇌졸중 환자를 대상으로 하였다. 대상자 선정조건은 다 른 신경학적 장애가 없는 자, 강직척도가 3 이하인 자, 다리에 구축이 없는 자, MMSE-K 점수가 24점 이상인 자로 하였다. 대상자 1은 64세, 남성, 뇌출혈로 인한 왼쪽 반마비, 발병기간 19개월, FAC scale 3점 이 었고, 대상자 2 은 58 세, 남성, 뇌출혈로 인한 오른쪽 반마비, 발병기간 23개월, FAC scale 3점이었다.

\section{2. 착용형 로봇보조기를 이용한 훈련}

착용형 로봇보조기(Tibion Bionic Leg, Tkbion Corporation, Sunnyvale, $\mathrm{Ca}, \mathrm{USA})$ 는 착용형이고, 이동이 가능한장치이다. 착용형 로봇보조기 는 벨크로를 이용하여 무릎관절에 감싸서 고정한다. 장치의 발바닥 과 무릎관절에 있는 센서가 움직임의 의도를 감지한다. 착용형 로봇 보조기의 설정은 장치의 보조를 시작하게 하는 역치값과 다리가 폄 되는 동안에 다리에 가해지는 체중지지의 비율값인 보조, 선 자세에 서 앉거나 계단을 내려갈 동안에 굽힙에 대한 저항의 단계를 조절할 수 있다. 보행 시 발바닥에 위치한 센서가 체중을 감지해서 일정량의 체중이 감소되면 무릎관절의 굽힘을 보조해 주고, 체중이 가해지면 무릎관절의 폄을 도와준다. 또한 앉고 일어서기 훈련 시 발바닥과 무
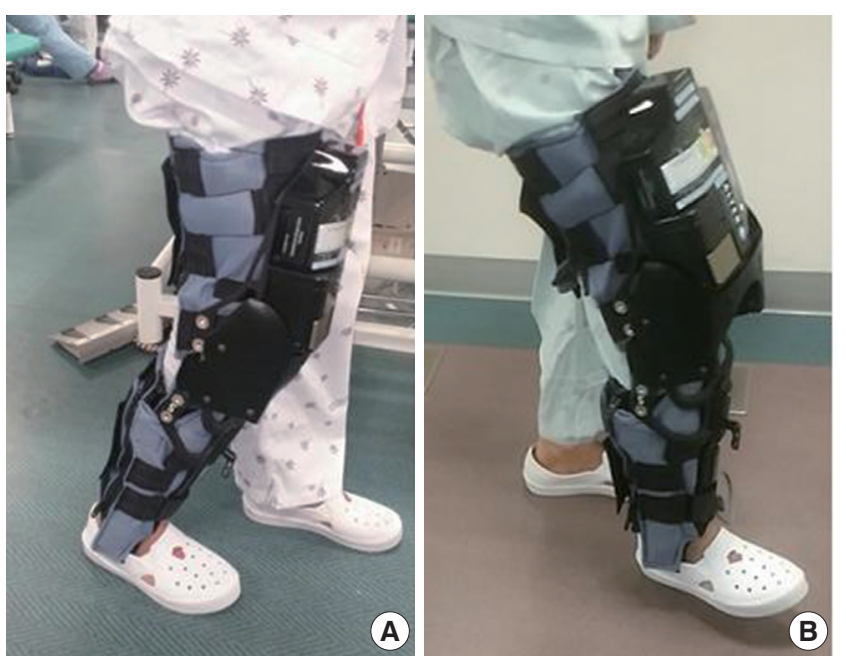

Figure 1. (A) Weight shift training utilizing wearable robot orthosis. (B) Gait training utilizing wearable robot orthosis.
릎관절에 위치한 센서는 치료 동안에 착용된 하지의 넙다리네갈래 근의 구심성수축과 원심성수축을 능동보조해 준다. 설정된 역치 힘 을 초과하게 되면 착용형 로봇보조기가 적절한 보조 또는 저항을 제 공하게 된다. ${ }^{8}$

훈련방법은 저항과 보조의 지표들은 환자의 근력, 보행행능력에 따라 점진적으로 조절하였다. 대상자들은 체중이동 훈련과 앉고 일 어서기, 지면보행, 계단 오르기를 주당 5 회, 하루에 40 분, 4 주 동안 총 20회 실시하였다(Figure 1).

\section{Measurement}

연구 대상자들의 보행능력를 측정하기 위하여 GAITRite (CIR System Inc., USA)를 이용하였다. 보행능력 측정을 위하여 먼저, 누운 자세에 서 전상장골극에서 족관절 내측과까지의 길이를 측정하여 입력한 후, 보행매트 전방 $2 \mathrm{~m}$ 에 서서 검사자의 구두신호에 의해 보행을 시작 하고, 가장 편안한 속도로 걸어서 보행매트를 지나 $2 \mathrm{~m}$ 까지 지나간 후 정지하도록 지시하였다. ${ }^{9}$ 대상자는 1 회 연습 후 3 회 측정하여 평균 값을 사용하였다. 공간적 변수를 위해 각각의 대칭성 지수를 구하였 다. 이 비율의 값이 0에 가까워질수록 보행 대칭성의 증가를 의미하 며, 0 에서 멀어질수록 보행 대칭성의 감소를 의미한다..$^{10} 3$ 회 반복 측 정하여 평균값을 사용하였다.

균형능력을 측정하기 위해 Biodex Stability System (Biodex Medical System Inc., USA)을 사용하였다. 피험자의 중심점은 검사 전에 발판 이 $5^{\circ}$ 이내에서 움직이도록 하여 설정하였다. 한 번 연습을 실시하고 본 측정을 실시하였다. 균형의 측정방법은 대상자가 발판 위에서 바 로 선 자세에서 모니터를 보면서 20초 동안 압력중심점을 중앙에 맞 추도록 하였다. 결과는 컴퓨터로 계산되어 균형지수가 출력된다. 균 형 지수가 높을수록 균형 수준이 낮다는 것을 의미한다. 이 도구의 측정자 내 신뢰도는 $r=0.80$ 이다."

Table 1. Comparison of functional outcome measure

\begin{tabular}{lccc}
\hline Measurement & Baseline & Post-intervention & Difference \\
\hline $\begin{array}{l}\text { Velocity (cm/sec) } \\
\text { Subject 1 }\end{array}$ & 16.5 & 26.4 & $60 \%$ \\
$\quad$ Subject 2 & 13.7 & 25.3 & $84.7 \%$ \\
$\quad$ Stance phase symmetry profile & & & \\
$\quad$ Subject 1 & 0.22 & 0.17 & $22.7 \%$ \\
$\quad$ Subject 2 & 0.25 & 0.21 & $16 \%$ \\
$\quad$ Swing phase symmetry profile & & & \\
$\quad$ Subject 1 & 0.42 & 0.36 & $14.2 \%$ \\
$\quad$ Subject 2 & 0.41 & 0.39 & $5 \%$ \\
$\quad$ Balance ability & & & \\
$\quad$ Subject 1 & 3.45 & 2.58 & $25.2 \%$ \\
$\quad$ Subject 2 & 2.89 & 2.04 & $29.4 \%$ \\
\hline
\end{tabular}




\section{결 과}

측정결과는 Table 1에 나타내었다. 보행속도는 대상자 1 이 $16.5 \mathrm{~cm} / \mathrm{s}$ 에 서 $26.4 \mathrm{~cm} / \mathrm{s}$ 로 $60 \%$ 향상되었고, 대상자 2 는 $13.7 \mathrm{~cm} / \mathrm{s}$ 에서 $25.3 \mathrm{~cm} / \mathrm{s}$ 으 로 $84.7 \%$ 향상되었다. 입각기 대칭지수는 대상자 1 이 0.22 점에서 0.17 점으로 $22.7 \%$ 개선되었고, 대상자 2 는 0.25 점에서 0.21 점으로 $16 \%$ 개 선되었다. 유각기 대칭지수는 대상자 1 이 0.42 점에서 0.36 점으로 $14.2 \%$ 향상되었고, 대상자 2 는 0.41 점에서 0.39 점으로 $5 \%$ 향상되었다. 균형능력은 대상자 1 이 3.45 점에서 2.58 점으로 $25.2 \%$ 향상되었고, 대 상자 2는 2.89점에서 2.04점으로 $29.4 \%$ 향상되었다.

\section{고 찰}

본 사례연구에서는 뇌졸중 환자에게 착용형 로봇보조기를 이용한 훈련을 실시한 후 보행과 균형능력에 변화가 나타나는지 알아보고 자 하였다. 4 주간의 훈련에서 보행속도와 보행대칭지수, 그리고 균형 능력에서 향상이 나타났다.

로봇을 활용한 재활훈련은 뇌병변 질환의 새로운 방법으로 제시 되고 있다. 아직까지는 보조적인 방법으로 사용되고 있고 운동능력 과 인지기능을 회복시키는 역할을 하고 있지만 신경학적 기전이 명 확히 밝혀지지는 않았다. ${ }^{12}$ 하지만 로봇재활은 일대일 치료시간을 줄 여 치료인력을 활용할 수 있는 장점이 있고, 착용형 로봇장치의 사용 은 다양한 활동을 가능하게 하여 일상으로 복귀를 촉진할 수 있어 비용을 줄일 수 있을 것이다.13 뇌졸중 환자에서 사용된 로봇장치들 은 주로 고정형으로 트레드밀 위에서 체중을 지지해주는 하네스를 통해 체중을 지지하고, 다리의 움직임을 도와주는 로봇이나 조절시 스템으로 구성되어있다. 이들 장비를 통한 보행훈련으로 운동기능의 향상과 더불어 뇌영역의 활성이 증가된 연구가 있다. ${ }^{14}$

뇌졸중재활은 환자가 기능적 과제로 부여된 문제들을 해결하기 위해 능동적으로 참여하는 것이 중요하다. 이러한 과제를 선택함에 있어 추상적 과제(abstract-tasks)보다 구체적 과제(concrete-tasks)를 설 정하는 것이 중요하다. ${ }^{15}$ 특히 뇌졸중환자의 기능 향상을 위해서는 일상의 환경 내에서 기능적인 움직임들이 수행될 수 있도록 목적 있 는 기능적 과제를 제공하는 것이 중요하다. ${ }^{16}$ 본 연구에서는 착용형 로봇보조기를 활용한 훈련방법으로 앉고 일어서기, 걷기, 계단 오르 기를 선택하였다. 이러한 훈련은 앉고 서기 운동, 평지 걷기, 계단 오 르기의 횟수를 증가시킬 수 있다. ${ }^{17}$ 이와 같은 향상은 체중을 지지하 는 동시에 하지의 움직임을 돕는 데 필요한 안정성을 증가시켜 준다. 마비측 하지의 체중지지 능력의 향상은 건측 유각기의 시간의 증가 를 가져온다. ${ }^{18}$ 점진적인 체중지지훈련은 동적보행지수와 보행 속도 와 능력의 향상을 가져온다. 본 연구에서도 보행주기 동안에 보장의
증가로 인해 보행속도의 향상과 함께 유각기와 입각기의 대칭성 지 수의 개선을 가져왔을 것이다.

균형능력은 일상생활에서 과제를 독립적으로 수행하고, 외부의 동요에 의해 자세를 유지하기 위해서는 필수적이다. 뇌졸중 환자의 균형증진을 위한 연구들을 보면 기능적 체중지지 훈련을 통해 중심 축의 움직임이 감소하고, 일어서 걸어가기 검사에서도 향상이 나타 난 연구 ${ }^{19}$ 와 동작관찰신체훈련을 적용해 균형이 향상된 연구 ${ }^{20}$ 모두 과제훈련을 적용하였다. 또한 가상현실을 이용한 로봇보조 보행훈련 을 적용한 연구에서도 버그균형검사와 뇌졸중 자세평가 척도에서 유 의한향상이 나타났다. ${ }^{21}$ 이 연구에서도 로봇다리보조기가 보행과 앉 고 일어서기 훈련을 통해서 환측에 체중부하를 유지하도록 보조해 주고 넙다리네갈래근이 오랫동안 수축할 수 있도록 속도를 조절해 주어 대상자들의 균형능력의 향상을 가져왔을 것으로 생각된다.

본 연구에서는 대조군을 설정하지 않았기 때문에 뇌졸중 후 물리 치료와 착용형 로봇 보조기의 효과를 구분할 수 없었다. 하지만 4 주 간의 중재기간에 보행과 균형이 기초선보다 눈에 띄게 향상된 것은 착용형 로봇보조기의 기여가 있었을 것으로 생각된다. 착용형 로봇보 조기는 손상으로 인한 부족한 하지의 기능을 도와줄 수 있는 역할을 해서 능력(capacity)에 부족하더라도 수행(performance)을 이끌어 낼 수 있다. 이로 인해 조기에 보행과 연관된 훈련들을 실시할 수 있다. 다 른 하지 로봇들과 비교해서도 부피가 작고, 경제적이어서 접근성이 뛰어나다. 이후의 연구에서는 착용형 로봇보조기를 이용한 그룹과 대조군의 집단 연구를 시행해서 추가 근거를 살펴봐야 할 것이다.

\section{ACKNOWLEDGEMENT}

This paper was supported by research funds provided from Howon University.

\section{REFERENCES}

1. Janet C, Roberta S. Neurological rehabilitation: optimizing motor performance. 2nd ed. New York, Churchill Livingstone, 2010:104-15.

2. Refshauge K, Ada L, Ellis E. Science-based rehabilitation: theories into practice. Elsevier Health Science, 2005:168-71.

3. Shim HB, Cho HY, Choi WH. Effects of the trunk stabilization exercise on muscle activity in lumbar region and balance in the patients with hemiplegia. J Kor Phys Ther. 2014;26(1):33-40.

4. Lee KH, Kim HS, Han DW, et al. The effect of bobath and conventional method in gait of adult hemiplegic patients. J Korean Soc Phys Med. 2008;3(4):277-84.

5. Mehrholz J, Werner C, Kugler J, et al. Electromechanical-assisted gait training with physiotherapy may improve walking after stroke. Stroke. 2008;39(6):1929-30. 
6. Ryerson SD. Hemiplegia. In: Umphred DA. Neurological rehabilitation. 3rd ed. St. Louis (MO): The C. V. Mosby Company; 1995:681-721.

7. Sale P, Franceschini M, Waldner A, et al. Use of the robot assisted gait therapy in rehabilitation of patients with stroke and spinal cord injury. Eur J Phys Rehabil Med. 2012;48:111-21.

8. Wong CK, Bishop L, Stein J. A wearable robotic knee orthosis for gait training: a case-series of hemiparetic stroke survivors. Prost Orthot Int. 2012;36(1):113-20.

9. Bilney B, Morris M, Webster K. Concurrent related validity of the GAITRite walkway system for quantification of the spatial and temporal parameters of gait. Gait \& posture. 2003;17(1):68-74.

10. Patterson KK, Parafianowicz I, Danells CJ,, et al. Gait asymmetry in community-ambulating stroke survivors. Arch Phys Med Rehabil. 2008; 89(2):304-10.

11. Arnold BL, Schmitz RJ. Examination of balance measures produced by the biodex stability system. J Athl Train. 1998;33(4):323-7.

12. Stein J. Robotics in rehabilitation: technology as destiny. Am J Phys Med Rehabil 2012;91(11 Suppl 3):199-203.

13. Stein J. Adopting new technologies in stroke rehabilitation: the influence of the US health care system. Eur J Phys Rehabil Med. 2009;45:255-8.

14. Wu C, Trombly CA, Lin K., et al. A kinematic study of contextual effects on reaching performance in persons with and without stroke: Influences of object availability. Arch Phys Med Rehabil. 2000;81(1):95-101.

15. Yoo JS, Park CH, Ha HG, et al. Neuroplasticity induced by robot-assisted gait training in a stroke patient-a case report. Brain \& NeuroRehabil. 2008;1(1):1-9.

16. Thielman GT, Dean CM, Gentile A. Rehabilitation of reaching after stroke: task-related training versus progressive resistive exercise. Arch Phys Med Rehabil. 2004;85(10);1613-8.

17. Horst RW. A bio-robotic leg orthosis for rehabilitation and mobility enhancement, Conf Proc IEEE Eng Med Biol Soc. 2009:5030-3.

18. Kim SH, Choi JD. The effect of gait training of progressive increasing in body weight support and gait speed on stroke patients. J Kor Phys Ther. 2013;25(5):252-9.

19. Lee JS, Nam KW, Kim KY, et al. Effect of weight bearing exercise on weight bearing and balance for patients with chronic stroke. J Kor Phys Ther. 2012;24(4):253-1.

20. Kim JY, Han KJ, Seo TH. The effects of action observational training and visualization training on balance and gait in stroke patients. Korea Entertainment Industry Association. 2012;6(4):305-12.

21. Lee DS, Lee KH, Kang TW, et al. Effect of early robot-assisted training using virtual reality program in patient with stroke. J Kor Phys Ther. 2013;25(4):195-203. 